\title{
A Framework for Enhancing ICT Competency of Universities in Sri Lanka
}

\author{
http://dx.doi.org/10.3991/ijet.v10i5.4802 \\ Champa Hewagamage ${ }^{1}$, K. Priyantha Hewagamage ${ }^{2}$ \\ ${ }^{1}$ University of Sri Jayewardenapura, Gangodawila, Nugegoda, Sri Lanka \\ ${ }^{2}$ University of Colombo, Colombo, Sri Lanka
}

\begin{abstract}
In the current information society, the need for securing human resources acquired with ICT competency is becoming a significant factor. Information Communication Technology (ICT) competency describes more than awareness or driving license level of using computing facilities and networking services to carry out different tasks. Undergraduates of a university will become knowledge workers in the society and they should acquire the knowledge, skills and attitudes using the modern ICT technology to carry out their job tasks effectively. This paper presents the current status of ICT Competency in Sri Lankan Universities with respect to both the knowledge and skill requirements of knowledge workers in the job market. However, there are several obstacles are affecting this development and the paper discuss the qualitative assessment of these obstacles in detail. In this study, we propose a new framework for enhancing the ICT Competency among a large number of undergraduates in the University system. This framework consists of two main components namely Infrastructure Development and Virtual Learning Environment. In the component, Infrastructure Development new facilities are provided such as computers, networks and Internet facilities, human resource management and other support services in order to solve the problems identified. Under the Virtual Learning Environment, we propose three levels for undergraduates to address the curriculums of ICT competency. The first two levels are declared with respect to the common ICT Competency Certification and level 3 is declared considering special requirements of curriculum or subject streams.
\end{abstract}

Index Terms-Curriculum Development, e-Testing, eLearning, Employability, Higher Education, ICT Literacy, ICT Competency, Relevance

\section{INTRODUCTION}

Information Communication Technology (ICT) competency describes more than awareness or driving license level of using computing facilities and networking services to carry out different tasks. Undergraduates of a university will become knowledge workers in the society and they should acquire the knowledge, skills and attitudes using the modern ICT technology to carry out their job tasks effectively. If they fail to achieve this level of competency in ICT, it becomes a key factor for the under or unemployment of graduates irrespective of academic qualification. Specially, when study streams of students are not in the science or engineering, it becomes an important as well as a difficult matter to be addressed in universities due to several reasons.
The current status of ICT Competency in Sri Lankan universities is much better than the ICT literacy in the society. This paper presents the current status of ICT Competency in Sri Lankan Universities with respect to both the knowledge and skill requirements of knowledge workers in the job market. The ICT literacy in the society is less than $20 \%$ in Sri Lanka irrespective of several national initiatives to improve it. However, ICT literacy in Universities is much higher and it has increased significantly from 2009 to 2013 . Since the university graduates will have to be knowledge workers in information society, they must have high capability using computing skills. ICT Competency was declared based on these requirements, where both the knowledge and skills required to use ICT in a workplace.

Majority of undergraduates in Sri Lanka will join the private sector employment where their business process strongly depends on the ICT based infrastructure. Hence, ICT based competency must be addressed irrespective of their core curriculum of study streams. It may help to improve the relevance and better employability. At the same time, it facilitates to enhance the quality of undergraduate education, and to establish the foundation for research studies in postgraduate education as a part of lifelong initiative of university education.

However, the development of ICT competency has become a tough assignment than expected, irrespective of investment to develop ICT infrastructure within the university during last 5-8 years. Our study showed several reasons affecting badly for this situation and heterogeneous user background was the key obstacle affected to enhance the ICT Competency. The user background includes the prior experience of using computers and Internet, English language and attitudes towards computing as the main factors. Different faculties in the university have their own programmes towards developing ICT literacy and the curriculum/syllabus of ICT competency courses were covering different scope without considering any national or international standards. ICT competency could be extended with respect to different study stream requirements in the final year of studies but the core competency must be common curriculum based on the knowledge, skill and attitudes of knowledge workers in the modern working environment. In this study, we have proposed three levels for undergraduates where first two levels address the core curriculum of ICT competency. The third level could be customized based on the faculty requirements with respect to study streams.

When the student numbers are large and their backgrounds are different, it is not effective to conduct the traditional teaching based on the classroom/laboratory 
PAPER

based environment to develop the ICT based competency. e-Learning based interactive and self-learning lessons create the learning environment to facilitate students to learn based on the requirements and backgrounds as well as depending on their availability. e-Testing based assessment on other hand creates an environment to assess the competency when students are ready to take the assessment. Based on the details of the qualitative assessment, we have proposed a framework for enhancing the ICT Competency among the large number of undergraduates in the Universities.

In this paper, we present the literature review based on ICT Literacy and Competency in the next section. Section 3 illustrates the status of ICT Competency in 2009 and 2013 considering all universities in Sri Lanka. Based on our experience on conducting this ICT Competency evaluation, we present our qualitative view on the importance of Enhancing ICT Competency in University education in the Section 4. ICT infrastructure is very important investment to develop the ICT competency of all stakeholders in a university. In section 5,we present some major issues that we observed in ICT infrastructure with respect to improving the ICT competency. Without setting up a suitable teaching and learning environment, it is hard to achieve the expectations of ICT Competency. Therefore, with integrating infrastructure development and teaching and learning environment, we propose a new framework for enhancing the ICT Competency among a large number of undergraduates as described in the Section 6. We summarize our discussion in Section 7.

\section{LiterATURE REVIEW: ICT LITERCY AND COMPETENCY}

The Information and Communication Technology (ICT) Literacy is a national issue of every country to be addressed and it has become a key performance indicator (KPI) to face the development goals in the $21^{\text {st }}$ Century.

The National ICT Competency Standards (NICS) [6] define the knowledge and skills an individual must possess at a recognized level of competence in specific ICT fields/areas. The competency standards on ICT will be used for performance management, professional development and professionalization of human capital in government, industry and academia. Each competency standard provides a common framework of expectations among government, business, educators, workers and students, such that:

- Government \& business are assured of manpower with the guaranteed ability to perform;

- Educators can discern the competencies on which curriculum is based;

- Workers understand what is expected to be performed and be more efficient \& productive; and

- Students know what they need to be able to do.

There are several different definitions about ICT literacy in the literature and they focus on the awareness and immediate use of ICT for limited tasks. This is a fundamental right of every citizen in a society like general education policy in a country. e-Citizen [2] and e-Sri Lankan [3] are kind of international and national programmes which highlights such requirements. These programmes provide a curriculum for a short courses as well as testing tools for certification. The ICT competency programmes could be considered as extended version of them with basic ICT applications in a networking environment with the following objectives:

a) Access the data/information through searching and browsing tools in order to collect them as the part of data gathering in a given problem context

b) Manage the collected data/information using a structured schema

c) Evaluate the data/information through the interpretation of facilities/tools to judge the quality, relevance, usefulness or efficiency.

d) Integrate the selected data/information within the process to add the value

e) Generating new data/information by adapting, applying, designing, inventing or authoring

It is very important to mention the ICT competency goes beyond the knowledge and skill of ICT tools and it requires the relevant individual to integrate with the cognitive skills such as language literacy, numeracy, and problem solving. Hence, the relevant ICT competency testing should include case study types of problems which are supposed to solve the given set of ICT applications in a supervised environment.

ICT is a transformative tool that will evolve rapidly in the society affecting one's culture, physical abilities, gender, educational, financial and geographical location. Hence, ICT will fundamentally change the way we live, learn, and work [4]. As a result of these changes, the quality of people's lives will improve due to the effectiveness of teaching and learning, the productivity of industry and governments, and the welfare of the society. In this context, the ICT competency will be a critical requirement of knowledge worker not only to join the workforce but also to survive or sustainability of his/her participation.

The research paper [7] expressed that ICT based competency must be addressed irrespective of their core curriculum of study streams and it may help to improve the relevance and better employability. According to the findings of [8], it is clear that the critical factor of institutional provision of ICT infrastructure has not yet been reached. One not only needs the infrastructure available, but also the personal skills in order to use ICT. It is evident from the literature that unless the issue of ICT competency is addressed, it can itself be a barrier to students' learning. They have suggested that special funds be created to revamp the e-learning support centres at the faculty level for students and faculty/staff use.

The researchers in [9] have identified the inadequate ICT facilities as one of the major challenges for ICT Competency among academic staff. The findings in [10] show that teacher's competency, teacher's confidence level and teacher's satisfaction toward ICT programmes are correlated among each other. And also it has indicated that teacher's satisfaction toward ICT training programme is a very important factor that can increase the levels of the competency and confidence.

\section{The CURRENT STATUS Of ICT COMPETENCY IN UNIVERSITIES}

In Sri Lanka, ICT literacy has become a political matter that has been discussed at various levels and stages. Various figures have been published by politicians but none of those statistics couldn't be verified from exiting sources. However, it is believed to be less than $20 \%$ in the society 
[1]. In the universities of Sri Lanka, several assessments have been carried out by independent parties from time to time. Two projects from the Ministry of Higher Education, IRQUE (Improving Relevance Quality in Undergraduate Education) and HETC (Higher Education in the $21^{\text {st }}$ Century) which are funded by the World Bank, carried out an independent evaluation of ICT competency status versus the investment for ICT infrastructure development in 2008 and 2013 respectively. Authors of this paper were consultants who coordinate the conduct of ICT literacy assessment across the universities in Sri Lanka. The findings of these two evaluations are presented in this section.

\section{A. IRQUE Evaluation 2009}

Improving Relevance of Undergraduate Education (IRQUE) is a project conducted by the Ministry of Higher education and it was funded by the World Bank. The main objective of this evaluation was to identify the ICT Competency in Universities after a significant investment on ICT infrastructure. The test consisted of three components, namely MCQ based knowledge test on IT, Word processing practical test and spread sheet based data management practical test. All universities (including some private universities) in Sri Lanka participated in the process as shown in the Fig. 3.1.

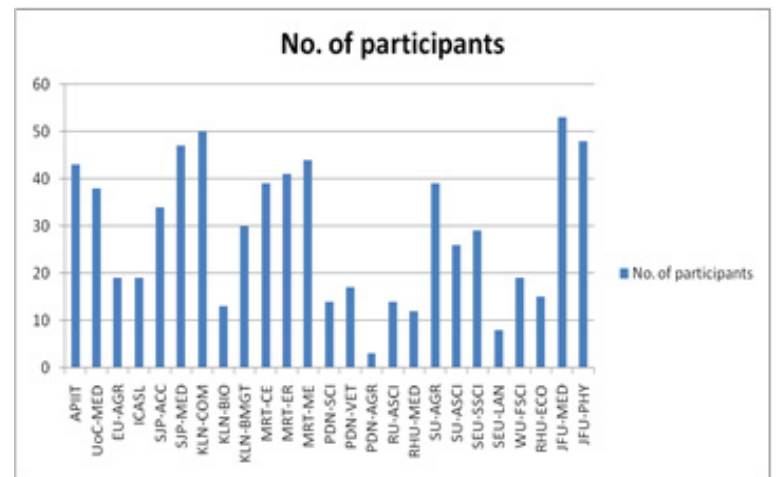

Figure 3.1. Student participation distribution on ICT Competency test with respect to universities (Total was more than 1500 students)

The Fig. 3.2(a), (b) and (c) show the details of performance with respect to those three tests. These three graphs indicate majority of students have the basic knowledge about ICT (around 50\%) but you can hardly find people who have very good knowledge about PC applications and Internet (over 70\%). On the other hand, they have some capabilities with respect to word processing $(40 \%)$ but they have very poor capabilities with respect to data management using spreadsheet (20\%).

After this evaluation, it was decided to conduct more common programmes to enhance the ICT competency, specially when students register degree programmes at national universities in Sri Lanka.

\section{B. HETC Evaluation 2013}

Higher Education in Twenty First Century is a current project conducted by the ministry of higher education funded by the World Bank and it is a kind of second phase of previous IRQUE project. More ICT investments were done in this phase of the project in order to enhance the ICT literacy of university students. An independent evaluation again carried out during the year 2013 and the summarize results were shown Table 3.1 and Fig. 3.3.

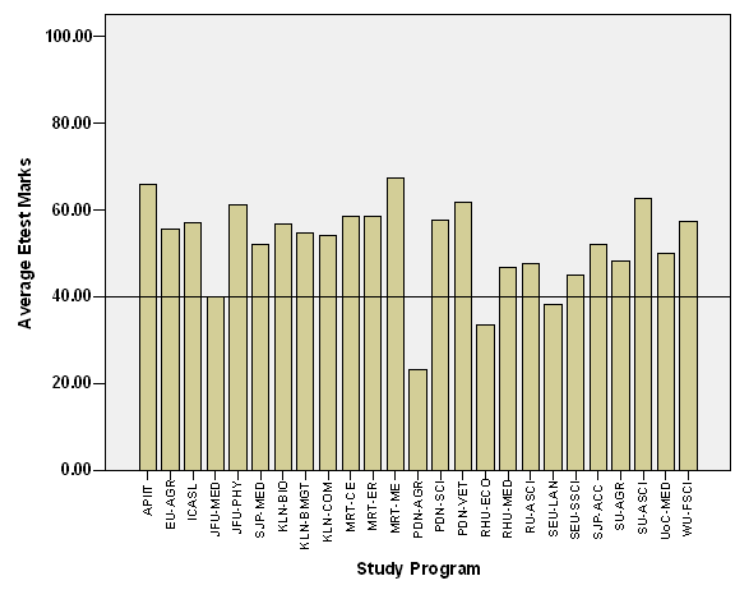

Figure 3.2 (a) Performance of ICT Literacy e-Test on IT Knowledge with respect to study programmes

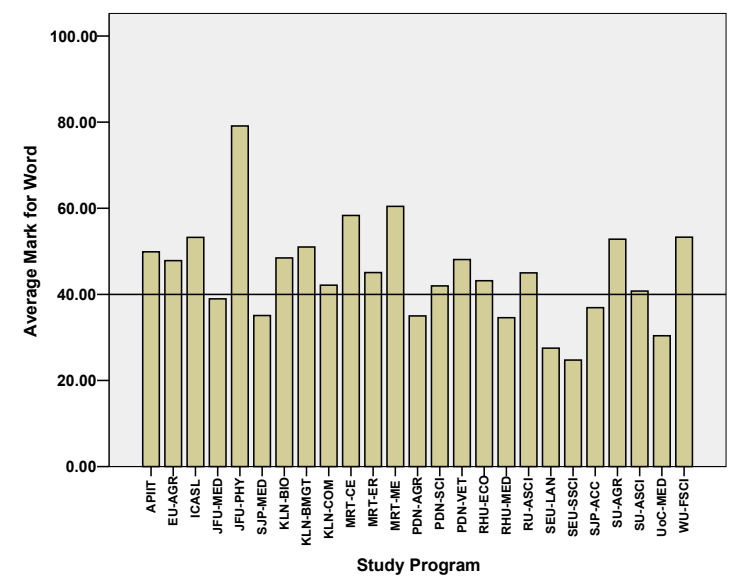

Figure 3.2 (b) Performance of ICT Literacy practical test on word processing wrt to each university

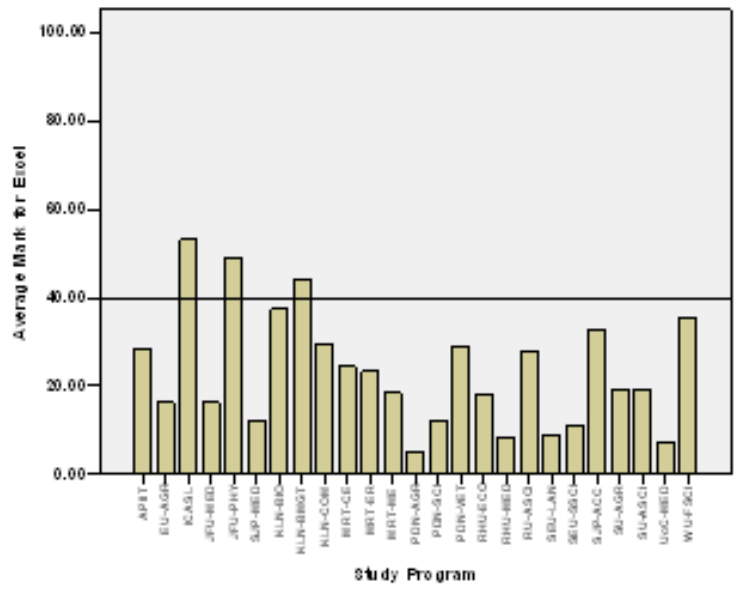

Figure 3.2 (c) Performance of ICT Literacy practical test on the spreadsheet management

The practical test was allowed only to students who were able to score more than 65 marks from the knowledge test in order to ascertain their skills in ICT competency. Word processing, spread sheet management, database management and presentation capabilities were evaluated in an equal way to ascertain their IT skills. Details are shown in the Fig. 3.4. 
TABLE 3.1

STUDENT PARTICIPATION (FROM ALL UNIVERSITIES) AND THEIR AVERAGE PERFORMANCE IN ICT COMPETENCY.

\begin{tabular}{|c|c|c|c|c|c|c|c|}
\hline & $\begin{array}{c}\text { Total } \\
\text { Stu- } \\
\text { dents }\end{array}$ & $\begin{array}{c}\text { Passed } \\
\text { (over 50 } \\
\text { mark) }\end{array}$ & $\begin{array}{c}\text { Passed } \\
\%\end{array}$ & $\begin{array}{c}\text { Aver- } \\
\text { age } \\
\text { Mark }\end{array}$ & $\begin{array}{c}\text { Stander } \\
\text { dization }\end{array}$ & $\begin{array}{c}\text { Max } \\
\text { Mark }\end{array}$ & $\begin{array}{c}\text { Min } \\
\text { Mark }\end{array}$ \\
\hline Total & 13814 & 8881 & $64 \%$ & 53.99 & 12.13 & 94 & 6 \\
\hline Male & 5035 & 3550 & $71 \%$ & 56.23 & 12.42 & 94 & 19 \\
\hline Female & 8775 & 5331 & $61 \%$ & 52.71 & 11.77 & 90 & 6 \\
\hline
\end{tabular}

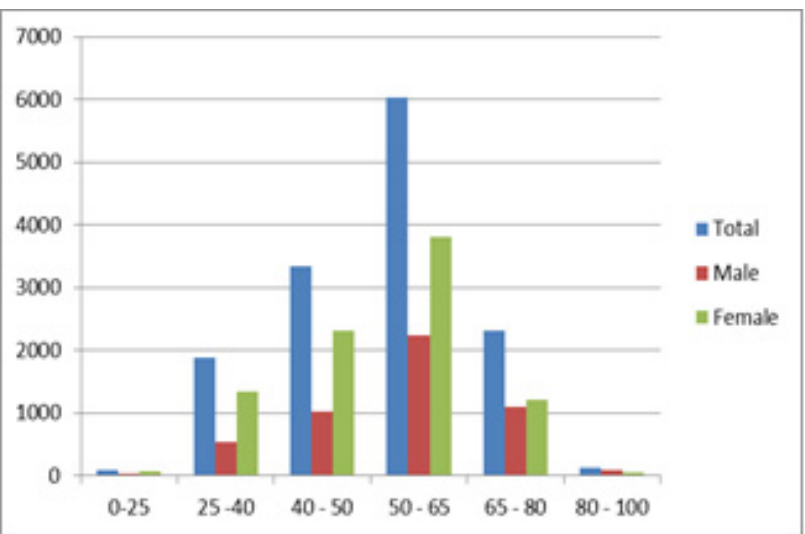

Figure 3.3 Analysis of Student Marks on ICT Competency Knowledge Test

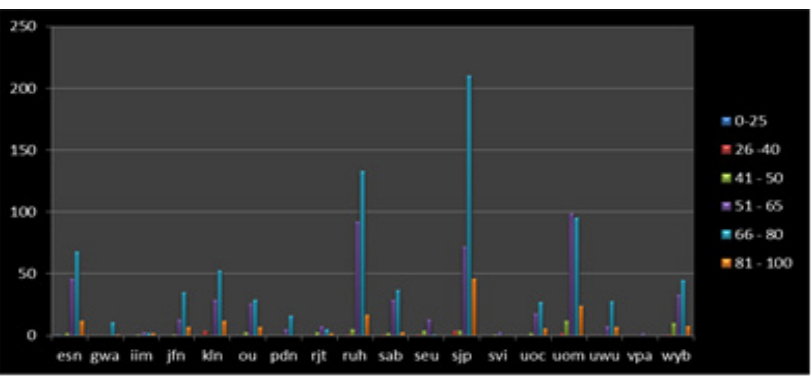

Figure 3.4 Analysis of ICT practical skills with respect to universities

\section{IMPORTANCE OF ENHANCING ICT COMPETENCY IN UNIVERSITIES}

There is growing international emphasis to drive the public and private investment and planning toward the knowledge-based economies and information-age societies. The Information and communication technologies are penetrating the home, the workplace, the marketplace, the government and community. Hence, the ICT Competency is a fundamental requirement of a graduate who will be employed in this knowledge based workplaces and the university education must be enhanced to this practical reality.

In addition to overall benefits of enhancing ICT competency, in this section we examine how ICT Competency could add the value for the university education.

\section{A. Study Streams}

In the investigation carried out in this project, we observed some study streams heavily depends on the ICT Competency of both students and teachers, namely science and engineering programmes. At the same time, academic contents and the development of subject matter directly or indirectly related with the ICT tools. Therefore, students and teachers have a kind of prerequisite to im- prove the ICT competency in order to engage or follow those study streams.

The study streams such as management and commerce have direct influence specially due to the way practices that are being carried out. For example, tools like Microsoft excel for spread sheet management is a common tool used for financial analysis in many organizations. However, the study streams in arts have indirect or minimal influence on the subject content. Therefore, courses do not consider any ICT literacy or competency when they are delivered.

Although the influence of ICT competency on study streams vary from one category to another category depending on their dependency, we observed all most all study streams subject content could be enhanced directly or indirectly through the proper curriculum development. However, teachers who are conducting these courses do not have adequate knowledge on ICT and/or are not interested to integrate the subject streams. If the ICT competency is not linked with the study streams, the relevant students are not taking any special attempt to increase or practice it. As a result of it, all courses to improve ICT literacy/competency are additional overhead which doesn't motivate students.

\section{B. Students Background}

In our investigation about ICT competency, we observed the students background also a critical factor that affects the university education. In order to follow programmes in higher education, students should be willing to participating learning activities in a collaborative environment. However, these students are joining with the university with various backgrounds irrespective of their selection results. For example, the English language knowledge and skill is one of key factor which demotivates students to follow ICT competency courses during the orientation programmes in the university. On the other hand, students who have some competency in English usually do have similar or adequate competency in ICT literacy (co-relations observed).

We also observed the student attitude as a factor that arises in their background that affects the ICT competency. Some students have negative attitude due to lack of experience in ICT. On the other hand, social development such as connecting friends through Facebook have made some positive attitudes about using computers and it indirectly motivates them to enhance ICT competency. For example, editing a photo image and sharing it with friends through the Facebook.

In the current secondary education system in Sri Lanka, there are courses about ICT at the GCE Ordinary Level and Advanced Level. Some students have followed them during their school time, and these students have very good competency level in ICT. However, there are some students, who didn't have a single chance to operate a computer before they are joining the university.

\section{Quality of Undergraduate Programmes}

The quality of undergraduate programmes was considered as a critical matter to be addressed in all universities in Sri Lanka. Various programmes and projects have been launched during the last decade by the Ministry of Higher Education with the help of many funding agencies. For example, IRQUE (www.irque.lk) and HETC (www.hetc.lk) projects. One of main objectives to consid- 
PAPER

er in these quality enhancement programmes/projects are to improve the employability (relevance) of study programmes. ICT Competency is directly related to the relevance and other quality factors in the higher education.

The Programme/Curriculum development, development of soft skills and understanding of peace and harmony are some of key activities that have been conducted to enhance the quality of undergraduate programmes. Setting up a learning management system to establish the blended learning environment within the university, as well as improving the knowledge and skill of web based course development and deliver (facilitation) among teachers are directly related activities under the programme activities linked to ICT competency.

ICT literacy and competency is a one of soft skills that we could consider among university undergraduates. At the same time, other soft skill activities such as organizing events, developing portfolios, marketing a product, and many others could be linked ICT based tools and hence they will contribute to enhance ICT Competency. Social networking is one interested tool to develop the social harmony among different groups inside a university. This could be done using internal social networking site or public social networks such as Facebook.

\section{Postgraduate studies and Lifelong Learning}

In universities, graduates/undergraduates are supposed to read their respective degrees. This approach is successful, if they are shifted from the teaching paradigm to learning paradigm. The first degree plays a key role in this paradigm shift. ICT enabled collaborative learning environment is the foundation for this paradigm shift in a university.

Research and development is the core part of postgraduate and lifelong learning process and it is impossible to carry out such research studies without ICT based environment and tools irrespective of study streams. Hence, we observed ICT competency play a key role to promote the postgraduate studies and lifelong learning in a university.

\section{MAJOR Issues For ENHANCING THE ICT COMPETENCY IN UNIVERSITIES}

ICT literacy couldn't be achieved by simply providing more and more computers for a university. The capacity enhancement play a vital role but all sectors of capacity enhancement should be addressed in a methodical way. In this section, we discuss issues related to different ICT Infrastructure for the ICT literacy.

\section{A. Computers for all}

One of starting issues in the infrastructure development for ICT usage, the availability or accessibility of computers. Both students and staff demand as the prerequisite, in order to promote ICT enabled teaching and learning environment. It is not possible to provide a high end personal computer for all teachers at once. Having a shared common computer lab dedicated for teachers was the first initiative. However, later a laptop mobile computer was provided for all senior staff members in the faculty. A training programme was too organized to enhance its usage, specially those teachers who have less experience on ICT literacy. However, the common lab is still the place for many junior teachers in the university. Addressing access to computers by teachers should be given a priority. We observed the opposite when these projects are implemented in some faculties. Administrators, who have less understanding about teaching and learning processing, gave the priority on setting up student computer labs.

Computer labs for students are also important initiative that must be carried out without much delay. However, setting up a lab as well as maintain the labs are equally important, otherwise there will be computer labs with small number of usable computers. The lowest cost approach when purchasing machines sometimes have affected badly due to less durable/reliable computers. We observed many broken machines in some computer labs. For example, a thing client approach was considered as the most cost effective approach for setting up student computer labs by some consultants in an evaluation. However, there were lot of practical issues and students cannot use those computers to do a photo editing in those machines.

It is time that we move from shared computers to private computers. Some students have managed to purchase a personal laptops but it is not the common situation of majority of students. At the same time, the popularity about tablet computers and smart phones among students are good opportunities to promote ICT competency. However, there are still no direct such initiatives targeting table computers or smart phones for education.

\section{B. Networking and Access to Internet}

Networking has become a compulsory feature required in modern computers. The main reason for networking is access to Internet or remote resources than local resources or sharing. Unfortunately, this has not been addressed in many universities properly compared student ratio. As a result, there are some access restrictions to Internet during some peak time intervals within the university. Detail investigation revealed, the main issue was due to the cost for high bandwidth and some administrators are not convinced paying very high bills for Internet bandwidth.

At the same time, we observed a very good initiative where a joined federation such as Learn (Lanka Education Research Network) [5] network which connects all universities through a main link and it was connected some special international links to quick and easy access to resources.

Some faculties facilitate their students to freely access Internet through the Wi-Fi network but some faculties have totally opposite view on such facilities and services. Unfortunately, there is no clear understanding and strict policy on this matter but access to networks/Internet within the campus will directly contribute ICT Competency of all stakeholders.

\section{Human Resource Development}

It is very important to maximize the usage of computers and integrate with their educational activities. It should not only for device to check one's email and browse new websites/social networks. Most importantly, teaching and learning activities should be integrated with ICT tools and it could be addressed using a specialized training programmes. It should be a continuous activity linked to staff development and/or workshops for students. In some universities, when they start similar course, there is a good participation in the first workshop but the gradual decrease in the rest of programmes. Unfortunately, there is no formal policy on such programme participation or evaluation of ICT. 
PAPER

A FRAMEWORK FOR ENHANCING ICT COMPETENCY OF UNIVERSITIES IN SRI LANKA

Some teachers demand personal laptop computers but they hardly use them or bring them to University. They believe that they have right to receive it but hardly consider them in using for teaching activities. This was due to lack of policies in universities about usage of ICT in teaching and learning activities. However, these situations were not constructive to enhance the ICT competency of all stakeholders and could be a kind of waste of resources.

\section{Help and other support services}

Technical troubleshoot is the most critical issue many staff members as well as students are facing when they want to use computers for teaching and learning activities. There is a small dedicated team in computer centres. Unfortunately, their service looks like a personal assistance to solve the issue without any learning process. Trouble shooting is a part of learning path of ICT Competency. All assistance should educate the learner what is really happening and it should not a black magic. Both parties should share and interact when solving any trouble shooting issues.

Many universities do not set up self-support services such as FAQs, User Guides, and a web site containing useful other resources for troubleshooting. Web based facilities could be used to make every user a part of community who can help others in a volunteer way.

Finding suitable tools and sites to carry out new tasks, and getting to know new tools are other important support services required for the continuous development of ICT Competency. The computer centre and computer society of a university could contribute significantly to establish this environment where stakeholders will find ways to improve their ICT literacy.

\section{The Proposed Framework For Enhancing The ICT COMPETENCY}

Once we understand the benefits of ICT Competency, the current status and the issues, it is important to integrate the requirements of ICT competency with the teaching and learning environment. Otherwise, it will not be possible to enhance both the ICT Competency and Teaching and Learning process in the university education system. With considering these requirements, we proposed a Framework for Enhancing ICT Competency for a large number of university Students as in Fig. 6.1.

This framework consists of two main components such as Infrastructure Development and Virtual Learning Environment. In the component, Infrastructure Development new infrastructure facilities are provided such as computers, Network and Internet facilities, Human Resource Management and other support services in order to solve the problems identified in the section 5. In this Virtual Learning Environment, we proposed the three levels for undergraduates to address the curriculums of ICT competency. The first two levels are declared with respect to the common ICT Competency Certification and level 3 is declared with considering special requirements of curriculum or subject streams. More details about the components of the framework are provided in below.

\section{A. Certification for ICT Competency}

It is very important to set up basic certification process for ICT Competency as a driving license to use computing equipment. This certification is not only for students but also for teachers who are given many free resources time

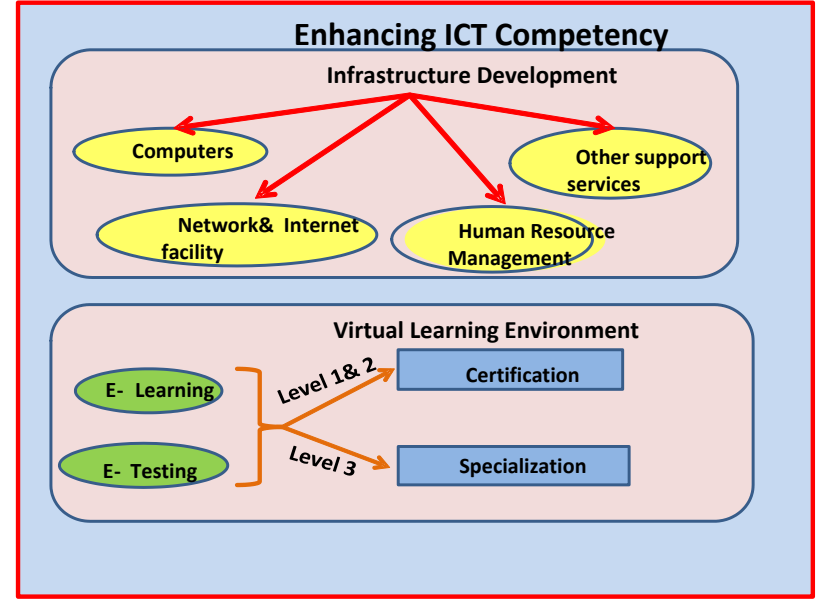

Figure 6.1 The proposed Framework for Enhancing ICT Competency

to time (to become eligible to receive equipment grants). This certification will eventually create an educated community who could promote to increase ICT Competency among new comers of the university.

The development of common curriculum across different student staff groups to educate them on the basic concepts and skills of using common office tools. Two levels could be declared with respect to common ICT Competency certification, where the level 1 is based on the knowledge assessment and level 2 is based on the skill assessment of basic office tools such as word processing, making presentation, spread sheet management and data handling in a database. It is hard to conduct common certification for both students and staff due to their formal role in the university. Therefore, it is better to have two approaches to implement the certification program.

The social activity such as award ceremony for ICT Competency Certification among students will give a good recognition and motivation for students to follow the programme before starting their academic programmes or while following the academic programmes.

\section{B. Specialization of ICT Competency}

First two levels of ICT Competency could be a core curriculum for all users in the university. However, level 3 could be declared considering special requirements of curriculum or subject streams of respective study programmes. At the same time, it could be an additional certificate specializing a particular area in ICT, for example, graphic design, network administration etc. These certificates will have added advantageous for students when they are seeking employment based on their academic qualification or special interests.

It is entirely the responsibility of relevant faculty to develop this specialization programme to enhance ICT Competency as a part of quality enhancement activity. However, there could be national level or university level initiatives to develop the level 1 and level 2 of ICT Competency.

\section{Virtual Learning Environment}

It is better to design ICT Competency development programmes as self-learning courses to minimize any disturbances to regular academic activities as well as to provide the training on demand basis. Those who have previous experience in using ICT tools could directly go 
PAPER

through the online courses and complete the learning activities to learn things which are new to him/her.

There could be special workshops at regular time points for those who need face-to-face assistance to follow the ICT Competency courses. At the same time, some recorded videos could be made available for those who find difficult to understand things by reading instructions.

\section{E-Testing in a Supervised Environment}

The virtual learning environment [VLE] (developed using a learning management system) could be used to give them for a model test before they take the formal test. Facilities in some VLEs help to conduct the e-Testing easily without setting up a new environment. For example, using a special password and ip number based control, MCQ testing for Level 1 and assignments for level 2 practical assessments could be developed easily.

Students could get to know their results on MCQ test immediately after the test and level 2 minimum mark could be set as the qualifying mark for the level 2. Adequate knowledge will be required before they take the practical test. There is no requirement of controlling number of attempts but the marking process of level 2 assessment requires an instructor's service. Hence, some control will be required when providing level 2 tests.

Students may want to select the test based on the tools they have used to learn relevant ICT applications, for example, MS Office or Open Office.

\section{DISCUSSION AND CONCLUSION}

In a developing country, like Sri Lanka, ICT literacy is a key factor for the national development in order to enhance the human resource capacity. Although there are courses in the secondary educational level that could be linked to ICT literacy, they are not very much popular in the rural areas due to lack of computing resources. As a result of this situation, students who are qualified to enter universities from rural areas are poor in ICT literacy and it badly affects their overall performance.

ICT Competency is a key factor that must be considered to enhance the university education in the $21^{\text {st }}$ Century. The ICT literacy in the society is less than $20 \%$ in Sri Lanka irrespective of several national initiatives to improve it. However, ICT literacy in Universities is much higher and it has increased significantly from 2009 to 2013. Since the university graduates will have to be knowledge workers in information society, they must have high capability using computing capabilities. ICT Competency was declared based on these requirements, where both the knowledge and skills required using ICT in a workplace.

In Sri Lankan Universities, the knowledge component of ICT Competency was around 50\% (pass mark was 50) in 2009 but it has increased $64 \%$ (pass mark was 50) in 2013 as a result of huge investment and other initiatives in higher education sector. However, only $20 \%$ was capable of score more than 65 marks and they were qualified to the second level of ICT Competency. In 2009, only word processing and spread sheet management were considered for skill assessment but in 2013, word processing, spread sheet management, making presentations, and database management areas were considered when evaluating ICT Competency due to requirements of knowledge workers in the current context. Out of $20 \%$ students who were qualified for skill assessment, only $70 \%$ of students were able to complete it successfully. i.e. around $14 \%$ from the overall population of university population.

When authors carried out their consultancy of assessing ICT competency, they observed several issues which are affecting ICT Competency of all stakeholders in the university community. This paper presents this qualitative discussion in detail and proposes a framework for enhancing ICT competency among undergraduates. The authors hope these issues could be corrected and it will have direct impact on increasing ICT competency in future.

\section{REFERENCES}

[1] Sri Lanka Computer Literacy, Department of Census and Statistics, http://www.statistics.gov.lk/cls/ [Last viewed 21 ${ }^{\text {st }}$ May 2014]

[2] E-Citizen Initiative, http://www.ecdl.org/media/CSB10_eSRI_LANKA1.pdf [21st May 2014]

[3] e-Sri Lankan Certification, National e-Learning Centre, UCSC http://www.e-learning.lk/onlineCourses/eSriLankan [21st May 2014]

[4] Framework for ICT Literacy, Educational Testing Service, http://www.ets.org/Media/Research/pdf/ICTREPORT.pdf [21st May 2014]

[5] Lanka Education Research Network (LEARN) http://www.ac.lk/ $\left[21^{\text {st }}\right.$ May 2014]

[6] National ICT Competency Standards, http://www.ncc.gov.ph/nics/index.htm

[7] C. Hewagamage and K.P. Hewagamage, "Developing ICT Competency among a large number of undergraduates in a University", Proceedings of $6^{\text {th }}$ International Conference on Education and New Learning Technologies, Barcelona, Spain, 7-9 July, 2014.

[8] R.B. Danner and C.O.A. Pessu, " A Survey of ICT Competencies among Students in Teacher Preparation Programmes at the University of Benin, Benin City, Nigeria”, Journal of Information Technology Education: Research, Volume 12, 2013.

[9] I.A. Archibong, J.E. Ogbiji and F.A. Idem, "ICT Competence among Academic Staff in Universities in CrossRivers State, Nigeria", Journal of Computer and Information Science, Vol.3, No.4, November, 2010.

[10] Z. Tasir, K.M.E.Amin, N.D.A. Halim and J. Harun, "Relationship Between Teachers' ICT Competency, Confidence Level, and Satisfaction toward ICT Training Programmes: A case study among postgraduate students", TOJET: The Turkish Online Journal of Educational Technology, Volume 11, Issue 1, 2012.

\section{AUTHORS}

Champa Hewagamage is Senior Lecturer at the Department of Information Technology, FMSC, University of Sri Jayewardenapura, Gangodawila, Nugegoda, Sri Lanka (champah@gmail.com).

K. Priyantha Hewagamage is Professor in Computer Science and the Head of the Department of Information Systems Engineering, University of Colombo, Colombo, Sri Lanka (kphewa@gmail.com).

Submitted 12 June 2015. Published as resubmitted by the authors 30 October 2015. 